\title{
Free Will as a Psychological Accomplishment
}

\author{
Eddy Nahmias \\ Department of Philosophy, Neuroscience Institute \\ Georgia State University \\ for the Oxford Handbook on Freedom (OUP, forthcoming) \\ edited by David Schmidtz and Carmen Pavel
}

This is the prepublication draft. Your library may have access to the online version:

http://www.oxfordhandbooks.com/view/10.1093/oxfordhb/9780199989423.001.0001/oxfordhb$\underline{9780199989423-e-30}$

\section{Free will as psychological capacity}

Imagine writing a philosophy paper or a short story. You imagine a range of options for presenting the argument or the plot, the structure, some sentences. But first, the opening line. You want to get it right. There are better and worse answers to the question: How should I begin? And regarding the rest: How should I proceed? To ask these questions requires the capacity to imagine a range of alternatives, and there are better and worse alternatives to imagine. To answer these questions requires the capacities to select among those alternatives, and there are better and worse ways to select them. People possess, to varying degrees, the diverse range of psychological capacities needed to write a philosophy paper or story: capacities to imagine a wider range of relevant options, to shift attention away from less - and towards more - promising options, to select the better options, and to execute these choices - making the imagined future the actual one. Furthermore, different people, in different situations, have better and worse opportunities to exercise these capacities - for instance, free time to let the mind wander and put words on paper. We don't know a lot about how these psychological capacities work or what underlying mechanisms explain their functioning (and malfunctioning). But when

the sentences flow from your exercising these capacities for imagination, attention, selection, and execution, well, then you are the author of your paper or your story. And you deserve some measure of credit for the good ones, culpability for the bad ones. 
So it is with free will, or so I will argue. For an agent to have free will is for her to possess the psychological capacities to make decisions - to imagine alternatives for action, to select among them, and to control her actions accordingly — such that she is the author of her actions and can deserve credit or blame for them. For an agent to choose freely (or act of her own free will) is for her to have had (reasonable) opportunity to exercise these capacities in making her decision and acting. There's a lot packed into these initial definitions, some of which won't be unpacked in this chapter. I will focus, first, on the under-appreciated point that these capacities for free will, like the capacities for writing, are possessed to varying degrees, and that people have better and worse opportunities to exercise them. Free will and free action are graded notions: we have degrees of freedom, and accordingly, degrees of responsibility.

Second, as with the capacities to write, the capacities that underpin free will have both structural and normative components. To have normative components means that the capacities can function more or less effectively. As with most capacities, such as those involved in biological reproduction, perception, riding a bike, or playing piano, there are criteria for what counts as their proper functioning, better and worse ways for them to be exercised. In the case of free will, as with writing, we cannot formalize these normative components. But clearly there are better and worse ways of writing a philosophy paper (ones we aim to teach our students) and better and worse papers (which we aim to assess properly when grading them). Similarly, there are better and worse ways of making decisions (ones we aim to teach our children) and better and worse decisions (which we aim to assess properly when we hold each other or ourselves morally responsible). As I discuss in section 2, there is a long philosophical tradition of treating free will as the set of capacities that, when properly functioning, allow us to make wise decisions, ones that contribute to our leading a good or flourishing life. On this view, free will is a psychological accomplishment.

Regarding structural components, capacities are typically composed of a number of other capacities, each of which is enabled by a complex organization of parts or mechanisms; in the case of our psychological capacities, these parts are primarily subserved by neural processes. Free will is often treated too simplistically, for instance, as a special metaphysical causal power or as a faculty to make decisions in light of one's reasons. While these views have features I hope to accommodate, other capacities have been under-appreciated-notably, capacities to imagine alternative future courses of action and capacities to control one's attention as one 
considers these alternatives. As with authoring a story, the ability to imagine various options and consider their merits is a crucial first step in the deliberative process, one that underlies our experience of freedom of choice, of having alternatives for action, with any alternative's occurrence causally depending on what one decides. Free will is not just about selecting among options, but also about imagining alternatives from which to choose (Sripada ms). Free will also includes our abilities to shape our non-deliberative, non-conscious mental activity and to shape our situations so that we act in accord with our goals even without exercising the capacities for conscious decision-making. Similarly, we are still exercising our capacities to write a story when we are lucky enough to have the words flow without our having, at each step, to imagine various options and choose among them.

While these psychological capacities for free will are remarkable, they do not require anything metaphysically mysterious. We are far from fully understanding how they work, but there is no reason to assume that they are non-natural or non-physical - that is, that they require causal powers that cannot be integrated into the mechanisms and laws that organize the physical world. ${ }^{1}$ While some have suggested that free will disappears in light of discoveries that we are physical beings governed by the laws of nature (e.g., Harris 2012), on my view, the sciences of the mind can help us discover how free will works (Nahmias 2014). Psychology and neuroscience will increasingly illuminate the mechanisms that underlie the capacities essential to free will, as they have with complex human capacities such as perception, language, and memory. These sciences are also discovering that we have less free will than we tend to thinkthat our capacities for decision-making do not always meet the normative criteria we think or hope they do.

Conversely, these sciences can also help us find ways to develop the relevant capacities more fully. Like other psychological capacities, we gain free will as we develop the relevant capacities. As a species, we attained these capacities through a fortuitous evolutionary history. As individuals, we develop these capacities as we mature, and we hope to raise our children to allow these capacities for free will to develop more fully. In the near future, we will increasingly develop methods to alter our psychological capacities more directly, using drugs or neural

\footnotetext{
${ }^{1}$ Whether free will requires that some of those laws are indeterministic is another question, but indeterminism is possible even if physicalism is true (as quantum physics shows), and such indeterminism might influence neural processes during human decision-making (see Kane 1996). Conversely, some problems allegedly posed by determinism remain even assuming a non-naturalist metaphysics (e.g., the impossibility of self-creation; Strawson 1986).
} 
interventions, potentially enhancing our free will and autonomy. We will have to make hard, hopefully wise, decisions about which of these interventions will contribute to human flourishing (Schaeffer et al. 2014).

\section{A brief history of free will}

Debates about free will have been overly obsessed with the question of whether free will is compatible with determinism, the thesis that the state of the universe at any time, in conjunction with the laws of nature, entails the state of the universe at any other time. This is so even though the status of determinism is for physics to discover, presumably with no notice of human psychology, and even though the dominant theory of physics suggests that determinism is false. The recent obsession with determinism was based in part on a definition of free will as the ability to do otherwise; for instance, Peter van Inwagen urges us to focus solely on "the free-will thesis" that "we are sometimes in the following position with respect to a contemplated future act: we simultaneously have both the following abilities: the ability to perform that act and the ability to refrain from performing that act" (2008: 329). A substantial proportion of work on free will in the past fifty years has been devoted to his Consequence Argument (1983) for the conclusion that determinism is incompatible with the ability to do otherwise and to Harry Frankfurt's argument (1969) that the ability to do otherwise is not necessary for moral responsibility (and perhaps free will).

These debates are fascinating and important. But they skew the discussion away from other important questions, including other potential threats to free will and other crucial components of free will. Increasingly, philosophers define free will as the set of abilities to control one's decisions and actions such that it is justified to hold one morally responsible for them - that is, such that one can deserve to be blamed or praised for them (O'Connor 2014; McKenna \& Coates 2015). On this view, there is more to free will than the ability to do otherwise. Most theorists recognize this, at least implicitly, whether they are compatibilists about free will and determinism or incompatibilists. Indeed, the disagreements among the competing theorists conceal a great deal of common ground regarding crucial capacities for free will, including cognitive capacities to consciously consider alternatives for action and to make choices based on one's reasons for action. 
Consider two compatibilist theorists. For Frankfurt an agent with free will possesses "the capacity for reflective self-evaluation" (1971: 12) and is "prepared to endorse or repudiate the motives from which he acts ... to guide his conduct in accordance with what he really cares about" (1993: 114). Jay Wallace describes similar capacities in terms of "reflective self-control: (1) the power to grasp and apply moral reasons, and (2) the power to control or regulate one's behavior by the light of such reasons" (1993: 157). Now consider two incompatibilist theorists. Laura Ekstrom states, “An agent enjoys freedom of action only if the agent's act results from a preference - that is, a desire formed by a process of critical evaluation with respect to one's conception of the good" (2000: 108). And Timothy O'Connor argues that free agents "such as ourselves are conscious, intelligent agents, capable of representing diverse, sophisticated plans of action," adding that he is "unable to conceive an agent's [freely] controlling his own activity without any awareness of what is motivating him" (2000: 121,88). And the list goes on. ${ }^{2}$ Most incompatibilists accept that these capacities for reflective and rational decision-making are both necessary for free will and compatible with determinism. But the debate focuses on whether some additional power or ability, such as agent-causation, is a further necessary condition for free will (see section 5).

Furthermore, the way earlier philosophers discussed free will suggests that they were not focused primarily on the ability to do otherwise, but instead on these capacities for reflection, self-knowledge, rationality, and self-control, often with an explicit normative component describing the proper functioning of these capacities. Michael Frede (2012) concludes his detailed history of the origins of the notion of free will by describing the shared features of the range of views he considers, from Aristotle to Stoics to Augustine and many others:

They all involve the idea that to have a good life one must be able to make the choices one needs to make in order to have such a life.... So, to be free, to have a free will, we have to liberate ourselves from these false beliefs and from attachments and aversions which are not grounded in reality. We can do this, moreover, because the world does not systematically force these beliefs, attachments, and aversions on us. (178) In other words, free will involves the capacities to make good choices, free from influences that distract and detract from such choices. This view of freedom as the set of capacities required to

\footnotetext{
${ }^{2}$ For instance, compatibilists Fischer \& Ravizza (1996), Nelkin (2011), Wolf (1990), 'agnostic' Mele (2006), libertarian Kane (1996), and skeptics about free will, Double (1991) and G. Strawson (1996).
} 
make good choices continues with figures such as Aquinas, Locke, Spinoza (a skeptic about libertarian free will), and Reid, a proponent of agent-causation, who points out that "moral liberty" requires "practical judgment or reason.... [without which] whatever the consequences may be, they cannot be imputed to the agent, who had not the capacity of foreseeing them, or of perceiving any reason for acting otherwise than he did" $(1788, \mathrm{IV})$.

We might use some other term, such as 'autonomy', to label the capacities for effective decision-making and self-determination described above, and reserve 'free will' as a philosophical term of art to refer to the ability to choose otherwise. But such a move would come at the cost of diverting us away from this historical tradition, from important strands of the contemporary discussion, especially those linking free will to moral responsibility, and from ordinary usage, which takes as paradigmatic of free will humans' uniquely well-developed capacities to deliberate consciously and to make choices without external constraint (e.g., Monroe \& Malle 2010).

In any case, my goal is not to offer an analysis of necessary and sufficient conditions for free will. Rather, my proposal for analyzing free will seeks reflective equilibrium among our ordinary experiences of, and intuitions about, free will, its usage in historical and contemporary discussions, and importantly, its connection with other psychological capacities, setting it up for scientific exploration rather than quarantining it from such exploration. I will, for the most part, assume compatibilism about free will and determinism, rather than arguing that it is the correct view (see Nahmias \& Deery, ms.) or that it is the intuitive view to most people, as long as they are not misunderstanding determinism to mean that the relevant psychological capacities are bypassed (Murray \& Nahmias, 2014). Regardless of whether compatibilism is true, however, the main points of this chapter go through. As suggested above, even incompatibilists think that the psychological capacities I describe are important features of free will or of an important variety of freedom. We need to analyze these capacities, to study their neuropsychological (structural) components, in part to understand the degree to which humans, and different individuals, possess them, and to consider their normative components, in part to understand how we might improve them and our opportunities to exercise them. 


\section{Some Neglected Capacities for Free Will}

Paradigmatic exercises of free will or free choice include some or all of the following components, each of which requires specific psychological capacities (referred to by number in what follows):

(1) Recognizing that a decision needs to be made.

(2) Imagining various options one might take-i.e., imagining different decisions one might make and the likely future outcomes of those decisions.

(3) Evaluating those options and imagined outcomes in light of one's desires, cares, values, goals, and plans. This process includes a capacity to shift attention towards or away from considerations one evaluates as more or less relevant. (Some of the most important decisions are about which of one's competing desires, values, goals, and plans one evaluates as more important than others.)

(4) Deciding-i.e., selecting an option.

(5) Forming relevant intentions to carry out that decision-i.e., forming proximal intentions (to act now), forming distal intentions (to act at some later time), or developing more general plans of action.

(6) When necessary, exercising willpower (or strength of will) to act in accord with these decisions, intentions, and plans.

A seventh capacity allows us to act freely — in accord with decisions we've made or at least with motivations we would accept if we considered them (Nahmias 2007) — and to be potentially morally responsible without going through the processes just described:

(7) Habituation and self-binding-i.e., carrying out actions that significantly increase the probability that one will act in accord with prior decisions or plans without conscious deliberation or intention-formation at the time of action, including making efforts to alter one's current habits, to regulate one's emotional reactions, and to structure one's environment to avoid competing temptations.

Some of these components are neglected in discussions of free will, perhaps because they are thought to be 'passive' rather than 'active'. Typically, we don't actively (or consciously) control whether and when a problem is posed requiring a decision (item 1) or which specific 
options come to mind as we deliberate (2), often relevant intentions follow automatically from decisions (5), and often we act without conscious deliberation (7). However, we sometimes engage in these processes in more active ways, consciously considering what decisions must be made today, trying to come up with more options to consider, actively shifting attention away from distracting or irrelevant options, and imagining specific action plans in order to prepare oneself to carry them out automatically (e.g., as when athletes or musicians imagine performances ahead of time). ${ }^{3}$ In any case, we should not assume that exercising free will only involves 'active' (e.g., voluntarily controlled) processes.

Conversely, philosophers, especially compatibilists, have focused their attention on the capacities to be reasons-responsive - recognizing and evaluating what reasons one has for various options (3) and accordingly deciding (4) and forming intentions (5) (e.g., Fischer \& Ravizza 1998, Wolf 1990). Others emphasize that the capacities for evaluation and decision must be properly sensitive to moral reasons (e.g., Wallace 1993, Scanlon 2008) or to which of our first-order desires we identify with (Frankfurt 1971). Finally, theorists are increasingly considering the role of willpower, as a limited resource, in free will (e.g., Baumeister \& Tierney 2011). For instance, exerting willpower may be necessary to carry out a proximal intention that conflicts with immediate desires (turning off the TV to go exercise) or to continue a plan when motivation has drained or other desires crop up (e.g., continuing to work on a philosophy paper as one fatigues or when one hears the ping of new email).

I favor casting a wider net and think we should recognize that all of these capacities are properly considered important components of free will. Each contributes to our capacity to make effective decisions and to act in ways that express the sort of person we want to be, such that we can be held accountable for so acting (Wolf 2015). Each of these capacities has normative features - criteria, even if controversial, for better and worse functioning. Each can and should be understood as graded - possessed to varying degrees with varying degrees of opportunity to exercise them. And each has structural features that can be naturalized and understood better with psychological and neurobiological research. Here, however, I want to focus attention on the neglected capacity of imagination (2).

\footnotetext{
${ }^{3}$ I am not claiming that any of the processes involved in 1-6 always occur with conscious awareness. We may be able to non-consciously evaluate options or form plans. It is an empirical question whether such processes can occur as effectively without conscious awareness as with it, but there is some evidence that conscious awareness is required for at least some complex mental processes and behaviors (Baumeister et al. 2011; Levy 2014).
} 
Our experiences of choice and free will clearly include the experience of there being multiple options for future action. It's contentious whether some of these experiences include (even implicitly) the content that these options are possible while also holding fixed all past and current conditions and laws of nature (Nahmias et al. 2004; Deery et al. forthcoming). But it should not be contentious that, once we recognize that a decision needs to be made (1), we typically imagine various future possibilities (2). As we consider these alternatives, we often begin imagining (consciously representing) the way they might play out, depending on what we do along the way, often letting our minds freely wander further 'downstream' into the future and into various 'offshoots' of the alternatives that may depend on later decisions.

These capacities to imagine options (and options within options) might seem to exaggerate what we ordinarily do during decision-making. I am not suggesting that we exercise these capacities every time we make decisions, nor that doing so is required for an action to be free, as is evident when we act automatically but autonomously using the relevant capacities (7). However, consider the planning you do as you shower, drive, or drift off to sleep, or your deliberations as you prepare and then write a paper, or recent experiences making a difficult decision, for instance, about what to tell a friend seeking advice or which of your competing projects should get priority. We sometimes risk obsessing over a decision-over-imagining and over-evaluating options - and may make efforts to stop and make a decision (4). Nonetheless, our imagination of future options is what explains not only our experience of freedom-of feeling free to actualize any one of a range of options we imagine if we choose it - but also our being free, since we often have the capacity and opportunity to actualize a number of options depending on which we choose (Sripada ms; Velleman 1989). Conversely, we are typically unable to choose an option that we have not even considered. Failures of imagination set limits to our freedom. ${ }^{4}$

These capacities for imagination are uniquely well-developed in human beings. Few other species have evolved the capacities for 'prospection' (or mental time travel), which allow

\footnotetext{
${ }^{4}$ While free will is often treated as an internal feature of agents (as in the trope that the prisoner in chains is unfree yet still has free will to choose how to react to imprisonment), this view neglects the importance of imagination to free will. Our circumstances can limit our opportunities for imagining options: we do not control which alternatives pop into consciousness as we consider what to do and we are not able to choose unimagined alternatives. For instance, regardless of their capacities, most women during most of history have been raised such that they lacked the opportunity to imagine many options for future action open to men. Such constraints, though not literal chains, limited women's opportunities to exercise their capacities for free will, such that these external constraints imposed internal constraints.
} 
us to represent scenarios far in the future, reason about their probabilities, and vary our representations of them consistent with features we hold fixed, such as the laws of nature or our goals. If other animals, such as apes or corvids, have these capacities, they appear to represent and plan only a short distance into the future (Suddendorf \& Corballis 2007; Gilbert \& Wilson 2007). This capacity appears to be related to and subserved by some of the same neural systems as other representational capacities involved in episodic memory, counterfactual reasoning, and mindreading. ${ }^{5}$

These representational capacities, including those involved in imagination, are compatible with the truth of determinism. Indeterminism is not required for it to be possible to imagine alternative future options or for it to be true that each of these options would (likely) occur were we to choose it. All we need here is 'epistemic freedom' to veridically believe that nothing prevents us from choosing among incompatible imagined options and that each one would be 'made true' by our choosing it (see Velleman 1989). ${ }^{6}$ These capacities are also consistent with naturalism, at least assuming that arguments that conscious mental states must be non-physical are unsound, as I believe they are. Assuming these representational capacities are in fact subserved by our remarkably complex brains, then neuropsychological explanations of imagination will offer explanations for much of our experience of free will. And assuming that neural processes involved in imagination and deliberation have appropriate downstream causal effects on our decision-making, then it will be inappropriate to say that these experiences are illusory (Nahmias 2014).

Why are these capacities for imagination particularly important for free will? First, as Chandra Sripada (ms.) convincingly argues, they provide "latitude for self-expression" (see also Seligman et al. 2013; Kennett \& Matthews 2009). They allow one to represent one's self in various future situations and evaluate whether each situation best achieves one's goals or event

\footnotetext{
${ }^{5}$ These capacities are subserved by the 'default network' in the brain, active when people are not carrying out other tasks and are instead mind-wandering or imagining (Raichle \& Snyder 2007). I suspect our capacities for imagination are dependent on, and evolved as side effects from, our capacities for 'mindreading' (prediction and explanation of others' behavior based on their mental states), which requires the ability to represent information not directly perceived but inferred from observable behavior. Human mindreading capacities may have evolved as part of a feedback loop of selection pressures for increasingly subtle deception and detection of deception within complex cooperative relationships (including reciprocal altruism). If so, then our ancestors ('Adam and Eve') gained free will from the fruit of knowledge of other minds and from the sins of subtly manipulating each others' minds and avoiding such manipulation.

${ }^{6}$ However, our experience of imagining alternative options, while we hold fixed other conditions, might help to explain our experience of choice as indeterministic (see Deery 2015).
} 
best expresses one's self-whether, for instance, one will be proud of or disappointed with the person one imagines in that situation. Like other animals, humans have the capacity to evaluate some options without consciously considering them, but just as we (presumably) cannot write philosophy papers entirely non-consciously, it seems unlikely that we can evaluate particularly complex options without consciously imagining them first.

Second, barring unlikely neurobiological discoveries suggesting the causal irrelevance of the neural activity that subserves imagination, our imagining options or failing to do so literally opens or closes possibilities for future action. Typically, one cannot successfully carry out complex actions, much less complex plans, unless one has imagined how to do so. Unimagined options are typically not really options. What we imagine is hence a difference-making cause in what we end up doing.

Third, imagination is properly tied to our attributions of responsibility. When we blame other people or ourselves for making poor or immoral decisions, we often say, "You should have known better." The implication is either that you did know better and still chose a worse alternative, perhaps motivated by self-interest or weak exertions of willpower, or that you failed to recognize better options. The latter is a type of failure of imagination. In such cases, it is sometimes true that you possess the capacities to imagine better options and had requisite opportunities (e.g., time) to exercise those capacities, and yet you failed to do so. "Think!" or "Think about how that would make him feel!" we say to our friends or children when they screw up, often meaning that they should have taken the time to try to imagine the possible (negative) effects of their actions and nothing prevented them from doing so. Again, concerns clearly arise here about determinism and what counts as a genuine ability or opportunity to exercise capacities differently than one actually does. But our ordinary attributions of responsibility seem to involve inquiry into whether the agent in question possessed the relevant capacities and had a reasonable opportunity to exercise them, both of which have plausible analyses consistent with the potential truth of determinism (e.g., Vihvelin 2013).

If we consciously recognize an option $O$ as a potential action that we have the capacities and opportunity to carry out, and we choose not to take it, then we are responsible for choosing not to. If we knew $O$ was a (morally) better option, then we are blameworthy for our choice. Conversely, we can be praiseworthy for imagining the better option, recognizing it as better, and choosing it. However, our control over what options come to mind during deliberation is limited. 
If we fail to imagine a better option than the one we choose, then it is difficult to determine whether we "should have (or could have) known better."

Here the role of attention in free will becomes relevant. The idea that we are able to bring to mind particular thoughts at will starts to look incoherent if we interpret it to mean that we can represent the content of the thought before we represent it or we have to consciously make a nonconscious idea conscious, and such thinking initiates a problematic regress. It's not clear that people think we have such incoherent abilities (contra Harris 2012). However, we do seem to have some degree of ability (a) to shift our attention towards, for instance, the general question, "Should I think more (or harder) about the consequences of making this choice or about options other than this one?" and (b) to shift our attention away from options that we evaluate as inconsistent with our values and goals, as too risky, as impossible to actualize, as irrelevant, etc. Developing these capacities for controlling attention as we imagine and evaluate options and their consequences is a significant goal of educating our children, students, and each other. Our capacity for free will improves as we improve our ability to attend to factors that are relevant to our deliberative task and to shift attention away from bad or irrelevant options.

We should be realistic about the extent to which we have direct volitional control over our imagination, evaluation, and attention. Instead, we may often control our decisions, to the extent that we do, in more indirect ways. These indirect methods, some of which are involved in habituation (7) are another under-explored aspect of our capacities for free will. One habit we may try to inculcate in ourselves and others is to regularly ask the question about whether to try to think more, but also to know when to stop asking it. We also have capacities to habituate, or re-habituate ourselves, so that we manage to act in accord with answers we would offer to these questions without having to consider them.

\section{Degrees of Freedom and Developing Free Will}

For some theories of free will, it's an awkward question when and how children get free will, and when and how our ancestors got it, especially within a naturalistic worldview without sharp boundaries based on new metaphysical entities, such as non-physical minds or new types of causation. On naturalistic views like mine, we can examine the structural components of capacities for free will to find some answers to these questions. This view is, however, consistent 
with threshold distinctions. Animals or infants with no capacity to imagine multiple future options do not possess free will. However, once the relevant capacities are in place, different species and different individuals can possess them to varying degrees. In contrast, existing discussions of free will seem to suggest that one either has it or doesn't, perhaps because the focus on determinism leads some incompatibilists to conclude we have no free will at all and others (libertarians and compatibilists) to argue that humans can have free will without much consideration of the degrees of freedom we have. ${ }^{7}$ Once we understand free will as a set of cognitive capacities, we can better consider what causes breakdowns in free will, including the usual suspects of addiction, compulsions, insanity, and other disorders of motivation or rationality, but also cases less often examined in which people's capacities for imagination or memory may be diminished (Kennett \& Matthews 2009).

In addition to individuals' possessing the capacities for free will to varying degrees, individuals have varying opportunities to exercise these capacities. We've all experienced that it's harder to exercise self-control (6) when tired or multi-tasking, but evidence now shows that the resources we use for self-control are limited and get depleted, though they can also be built up with practice (Baumeister \& Tierney 2011). Opportunities to exercise one's capacities for imagining future options can be limited by external constraints imposed by one's culture (note 4). They can also be limited by situational factors we do not recognize and would not want to influence us if we knew about them (Nahmias 2007). For instance, in bystander intervention experiments, the presence of passive bystanders prevents some subjects from imagining the situation as one in which their help is required (see Ross \& Nisbett 1991). Lack of time and energy clearly impose limits on our opportunities to imagine options or properly evaluate them. To the degree that we can minimize these limitations, however, we can increase people's opportunities to exercise their free will.

Finally, we have varying degrees of freedom, and potential for developing free will, because of the normative component of the relevant capacities. Our students may have the structural capacities to write philosophy papers and ample opportunity to exercise them, but they

\footnotetext{
${ }^{7}$ Note that compatibilism is just a claim about the possibility of free will in a deterministic universe, not the thesis that humans actually have it. Yet historically, all compatibilists have suggested that humans have free will and have focused little attention on other potential threats to free will (e.g., epiphenomenalism or limitations on our capacities for rational decision-making) or the degree to which such threats may be actual for humans. "Cagey compatibilism" is my name for the view that says determinism is irrelevant to free will but other theses and potential scientific findings are relevant to free will and could suggest we have less than we think
} 
have varying abilities to write good papers. Determining the normative criteria for possessing effective capacities for, and admirable exercises of, free will is at least as difficult as answering many other normative questions. But let me briefly offer three suggestions.

First, there are two 'internal' criteria for effectively exercising free will. One is imagining options that will advance one's goals, values, and interests, as one understands them. People succeed in exercising free will to the extent that they imagine new and more effective ways of acting to achieve their own goals and to act in accord with their values. Indeed, people feel more free when they imagine better options and effectively select one, more so than when they simply imagine more options or remain uncertain about which to select (Lau et al. 2015; Nahmias et al. 2004). A second criterion involves managing to actualize what one has imagined as the best future course of action, primarily by forming effective intentions and plans (5) (Bratman 1987), exercising self-control as necessary (6), and habituating oneself to act accordingly (7). Both of these internal criteria involve making one's imagined future match the actual future, but neither requires that the goals or values one succeeds in carrying out are actually good, morally or pragmatically.

The third criterion for accomplishing free will is more 'external.' It involves imagining, evaluating, and actualizing options that advance the goals, values, and interests that one should have. Here, the view Frede attributed to historical figures comes to the fore, since it suggests that free will includes the capacity to make choices that will contribute to a good or flourishing life (cf. Wolf 1990). I find this idea attractive, since I think it takes imagination and creativity to recognize options better than existing ones, including for our own life and our culture, and options that are better than our more 'default' behaviors (e.g., to be self-interested or to act on immediate motivations rather than on other-directed or long-term interests). To the extent that we can imagine new options, including better goals or values and better ways of achieving existing goals, we gain freedom.

There is a seemingly paradoxical feature of this view. Those individuals who possess to lesser degrees the capacities for free will, or have worse opportunities to exercise them, will often be the individuals who make bad choices, ones that negatively impact their own and others' lives. If so, the people who make choices we are most inclined to blame, or most resent, are often those who, on this view, are less responsible for those choices. I think this is a feature we should learn to live with. Once we better understand the limitations on free will, we should accordingly 
cultivate both forgiveness towards, and a desire to help develop, the capacities and opportunities of those who make bad choices due to these limitations. I take this response to be more humanistic and pragmatic than the one suggested by those who argue that we all lack free will entirely, so that no one genuinely deserves any blame or retributive punishment, a view which suggests we should treat wrongdoers on a disease model that requires rehabilitation when possible, and quarantine when not (e.g., Harris 2012; Pereboom 2014).

It may also turn out that we all possess the relevant capacities and opportunities to a lesser degree than we tend to think. For instance, we may be 'built' not to prospectively imagine and evaluate options rationally but instead to rationalize and justify our existing motivations and prior decisions. And we may be influenced by unnoticed situational factors or unconscious biases significantly more than we think. If so, then empirical investigation may help us recognize these limitations and ways to overcome them.

\section{Free Will as Forward-looking}

The views developed in this chapter suggest that free will involves a set of skills or knowledge. The capacities for imagining possibilities for action and their potential outcomes allow us to know what we could do. The capacities for evaluating these options allow us the potential to know what we should do. And the capacities involved in self-control and habituation involve knowing how to do what we decide or plan to do.

Agents have free will to the extent that they possess these capacities for imagination, decision-making and self-control. They "have what it takes" to act of their own free will and to be responsible for what they do. Such agents do not always have the opportunity to exercise these capacities when they act. They may be constrained by external pressures or persons or compelled by internal pressures in such a way that they have no (or less) reasonable opportunity to exercise their capacities for free will. Without such opportunities, they are typically not responsible (or less responsible) for that action. Finally, agents may or may not actually exercise their capacities for free will even when they do have the opportunity to. If they do, they will typically be responsible (and blameworthy for bad choices, unless they could not be expected to have known relevant obligations or information). If they do not exercise their capacities for choice and control even though they had the opportunity, then they are also typically responsible, 
in this case for their failure of imagination, attention, or effort ("You should have known better" or "You should have tried harder"). Hence, if agents are not exempt because they lack the relevant capacities for free will or if agents are not excused because they lack the relevant opportunity to exercise these capacities, then they are responsible for what they do. They deserve credit or blame for their actions; they are an appropriate target of gratitude or resentment; it may be fair to reward or punish them (Strawson 1962). ${ }^{8}$

Those used to the traditional philosophical debates about free will may still be wondering how the capacities for free will I've described help answer the ancient worries about determinism or more recent worries about naturalism. This chapter has not focused on answering arguments that free will is incompatible with determinism or naturalism. In part because I think the default or intuitive view is neither incompatibilist nor non-naturalist (Nahmias et al. 2014), I think compatibilists should not play defense so much. Rather, we should offer the most viable positive account of how our capacities for imagination, decision-making, and self-control work and how they explain our experiences of and beliefs about free will, and only then consider whether they require indeterminism or more 'metaphysically robust' powers.

Here, I've asked us to focus on the forward-looking features of free will, especially our psychological capacity to imagine future possibilities that do not yet exist, as well as capacities to shift our attention towards possibilities that cohere with our goals and values and to habituate ourselves to act accordingly. Once we focus on these capacities, we can ask whether they could exist and have the appropriate causal relations with future behavior if it turned out that determinism or naturalism were true.

Responding to the 'bottom-up' problem of naturalism is relatively easy. It is a mistake to think that our forward-looking capacities are causally irrelevant, or bypassed, if they are subserved by neural processes. Instead, naturalism simply suggests that we will eventually understand how free will works in the brain, not that we will or should come to see it as an illusion because it works in the brain. Assuming the eventual neurobiological theory of our conscious representational capacities does not eliminate their causal role, then there is no reason to assume naturalism threatens free will (Nahmias 2014). The fact that, in some sense, "my brain

\footnotetext{
${ }^{8}$ I say 'may be' fair because there are moral questions about when and what types of punishment are fair that go beyond questions of free will. Compatibilists are sometimes expected establish that we can have the sort of free will that justifies retributive punishment, but there may be independent reasons to reject the fairness of some forms of retribution.
} 
did it" does not compete with my having done, and recognizing this allows us to see that naturalism does not entail bypassing of our conscious selves or of our capacity to shape our future lives based on what we imagine them to be.

The 'backwards-looking' problem of determinism is more difficult to brush aside. One worry is that determinism would entail that we can never do otherwise, never have an opportunity to exercise our capacities for choice differently than we actually do. Though it won't satisfy many incompatibilists, this worry is best addressed by arguing that the ability to do otherwise, holding fixed all conditions and laws, is not the best analysis of the capacities and opportunities required for free and responsible agency (e.g., Vihvelin 2013).

Another worry is that determinism would entail that we are not the causal source of our decisions because they have prior causes ultimately beyond our control (this worry does not dissipate even if some causes are indeterministic). Again, by focusing on the forward-looking causal effects of our capacity to actualize one, among several, imagined future options, we can recognize that determinism does not entail bypassing of these causal effects, which will diffuse some of the more intuitive threats from determinism (Murray \& Nahmias 2014). Furthermore, determinism does not entail that there are any particular variables beyond our control (e.g., in the distant past) that cause our decisions; instead, our deliberations are the nexus of an everexpanding set of prior causes, such that, among those causes, our exercising our capacities for free will can often be picked out as the causal difference-maker, or most significant causal explanation, for our actions. Even if determinism is true, no variable better explains some of our decisions than the variables involved in our imagining and evaluating future options (Nahmias \& Deery ms.).

Even if one imagines some further condition for free will would somehow provide a more satisfying response to these alleged threats from naturalism or determinism, the capacities I've identified with free will are a psychological accomplishment. We can imagine and write our own stories in impressive ways that open up real options unavailable to creatures lacking these capacities. ${ }^{9}$

\footnotetext{
${ }^{9}$ For helpful comments on this chapter, I thank Chandra Sripada, Andrea Scarantino, Oisin Deery, Adina Roskies, and participants at a workshop at the Center for the Philosophy of Freedom at University of Arizona.
} 


\section{References}

Baumeister, R.F., Masicampo, E.J., \& Vohs, K.D. (2011). Do conscious thoughts cause behavior? Annual Review of Psychology, 62, 331-361.

Baumeister, R.F., \& Tierney, J. (2011). Willpower: Rediscovering the greatest human strength. New York: Penguin Press.

Bratman, M. (1987). Intentions, plans, and practical reason. Cambridge: Harvard University Press.

Deery, O. (2015). Why people believe in indeterminist free will. Philosophical Studies, 172(8), 2033-2054.

Deery, O., Davis, T., \& Carey, J. (2015). The free-will intuitions scale and the question of natural compatibilism. Philosophical Psychology, 28(6), 808-814.

Double, R. (1991). The non-reality of free will. New York: Oxford University Press.

Ekstrom, L. (2000). Free will: A philosophical study. Boulder: Westview Press.

Fischer, J.M. \& Ravizza, M. (1998). Responsibility and control: A theory of moral responsibility. Cambridge: Cambridge University Press.

Frankfurt, H. (1993). On the necessity of ideals. In Necessity, Volition, and Love. Cambridge: Cambridge University Press.

Frankfurt, H. (1971). Freedom of the will and the concept of a person. In The Importance of What We Care About. Cambridge: Cambridge University Press.

Frankfurt, H. (1969). Alternate possibilities and moral responsibility. In The Importance of What We Care About. Cambridge: Cambridge University Press.

Frede, M. (2012). A free will: Origins of the notion in ancient thought. Berkeley: University of California Press.

Harris, S. (2012). Free will. New York: Free Press.

Gilbert, D., \& Wilson, T. (2007). Prospection: Experiencing the future. Science, 317, 1351-54.

Kane, R. (1996). The significance of free will. New York: Oxford University Press. 
Kennett, J., \& Matthews, S. (2009). Mental time travel, agency and responsibility. In M. Bortolotti (Ed.), Psychiatry as Cognitive Neuroscience: Philosophical Perspectives.

Lau, S. Hiemisch, A., \& Baumeister, R. (2015). The experience of freedom in decisions Questioning philosophical beliefs in favor of psychological determinants. Consciousness and Cognition, 33, 30-46.

Levy, N. (2014). Consciousness and moral responsibility. New York: Oxford University Press.

McKenna, M. \& Coates, D.J. (2015). Compatibilism. Stanford Encyclopedia of Philosophy, E. Zalta (ed.).

Mele, A. 2006. Free Will and Luck. New York: Oxford University Press.

Monroe, A. \& Malle, B. (2010). From uncaused will to conscious choice: The need to study, not speculate about people's folk concept of free will. Review of Philosophy and Psychology, 1, 211224.

Murray, D., \& Nahmias, E. (2014). Explaining away incompatibilist intuitions. Philosophy and Phenomenological Research, 88, 434-467.

Nahmias, E., \& Deery, O. (unpublished). Defeating manipulation arguments: Interventionist causation and compatibilist sourcehood.

Nahmias, E., Morris, S., Nadelhoffer T., \& Turner, J. (2004). The phenomenology of free will. Journal of Consciousness Studies 11, 162-179.

Nahmias, E., Shepard, J., \& Reuter, S. (2014). It's OK if 'my brain made me do it': People's intuitions about free will and neuroscientific prediction. Cognition, 133, 502-513.

Nahmias, E. (2014). Is free will an illusion? Confronting challenges from the modern mind sciences. In Moral Psychology, vol. 4, Free Will and Moral Responsibility, W. SinnottArmstrong (ed.), MIT Press.

Nahmias, E. (2007). Autonomous agency and social psychology. In Cartographies of the Mind, Marraffa, Caro \& Ferretti (eds.), Springer.

Nelkin, D. (2011). Making sense of freedom and responsibility. New York: Oxford University Press. 
O’Connor, T. (2014). Free will. Stanford Encyclopedia of Philosophy, E. Zalta (ed.).

O'Connor, T. (2000). Persons and causes: The metaphysics of free will. New York: Oxford University Press.

Pereboom, D. (2014). Free will, agency, and meaning in life. New York: Oxford University Press.

Raichle, M. E., \& Snyder, A. Z. (2007). A default mode of brain function: a brief history of an evolving idea. Neuroimage, 37, 1083-90.

Reid, T. (1788). Essays on the active powers of man.

Ross, L. \& Nisbett, R. (1991). The person and the situation: perspectives of social psychology. New York: McGraw-Hill.

Scanlon, T.M. (2008). Moral dimensions: permissibility, meaning, blame. Harvard University Press.

Schaeffer, G.A., Kahane, G., \& Savulescu, J. (2014). Autonomy and enhancement. Neuroethics, 7, 123-136.

Seligman, M., Railton, P., Baumeister, R., \& Sripada, C. (2013). Navigating into the future or driven by the past. Perspectives on Psychological Science, 8, 119-141.

Sripada, C. (unpublished). Free will and the construction of options.

Strawson, G. (1986). Freedom and belief. Oxford: Clarendon Press.

Strawson, P. (1962). Freedom and resentment. Proceedings of the British Academy 48, 1-25.

Suddendorf, T., \& Corballis, M. (2007). The evolution of foresight: What is mental time travel, and is it unique to humans? Behavioral \& Brain Sciences, 30, 299-313.

van Inwagen, P. (2008). How to think about the problem of free will. Journal of Ethics, 12, 327341.

van Inwagen, P. (1983). An essay on free will. Oxford: Oxford University Press.

Velleman, D. (1989). Epistemic freedom. Pacific Philosophical Quarterly 70, 73-97. 
Vihvelin, K. (2013). Causes, laws, and free will: Why determinism doesn't matter. New York: Oxford University Press.

Wallace, J. (1993). Responsibility and the moral sentiments. Cambridge: Harvard University Press.

Wolf, S. (2015). Responsibility, moral and otherwise. Inquiry, 58, 127-142.

Wolf, S. (1990). Freedom within reason. New York: Oxford University Press. 